\title{
A desconstrução da ordem do discurso e a violência simbólica nas Orientações Curriculares Nacionais: em questão a identidade do sujeito-professor
}

\author{
Alex Pereira de Araújo \\ Universidade Estadual de Santa Cruz ${ }^{1}$ \\ Universidade Estadual do Sudoeste da Bahia \\ alex.scac@hotmail.com
}

\section{Resumo}

Sobre a política linguística nacional veiculada nas Orientações Curriculares Nacionais de Português no ensino médio, cujo discurso se traduz em um método sofisticado de controle e em uma forma eficaz de gerir a mudança, é o que buscamos refletir neste trabalho. Nesse sentido, podemos dizer que "todo sistema de educação é uma maneira política de manter ou de modificar a apropriação dos discursos, com os saberes e os poderes que eles trazem consigo" (FOUCAULT, 1996, p. 45). Com base na abordagem discursivo-desconstrutiva (CORACINI, 2003a), pretendemos apresentar e discutir os resultados analisados, cujo foco recai sobre as representações da(s) identidade(s) e das competências construídas para os professores neste discurso, representações sociais da profissão do professor na sociedade contemporânea brasileira, marcada pelos acontecimentos que sucederam o período ditatorial, portanto, a fase de redemocratização do país e de modernização do Estado frente às exigências da mundialização.

Palavras-chave: desconstrução; discurso; identidade; sujeito-professor

1 Participa como pesquisador dos Grupos de Pesquisas Traduzir Derrida Políticas e Desconstruções da UESC e do GRUDIOCORPO da UESB. É bolsista CAPES pelo programa de Pós-Graduação em Memória: Linguagem e Sociedade (doutorado) da Universidade Estadual do Sudoeste da Bahia, atuando também no Curso de Letras Vernáculas EaD da Universidade Estadual de Santa Cruz (Ilhéus-BA)/Universidade Aberta do Brasil.

Horizontes de Linguística Aplicada, ano 11, n. 2, jul./dez. 2012 


\section{Abstract}

On the national language policy conveyed the Portuguese National Curriculum Guidelines (high school), whose speech translates into a sophisticated method of control and an effective way to manage change is to reflect what is sought in this work. In this sense, one can say that "the whole system of education is a political way of maintaining or modifying the appropriation of discourse, with the knowledge and power they bring with them" (Foucault, 1996, p. 45). From the discursive-deconstructive approach (CORACINI, 2003a), we intend to present and discuss the results analyzed here, whose focus is on the representation (s) of identity (s) and built skills for teachers in this discourse, social representations of teaching profession in Brazilian contemporary society, marked by the events that followed the dictatorship period, so the phase of the country's democratization and modernization of the state to the demands of globalization.

Keywords: deconstruction, discourse, identity, subject-teacher

\section{Introdução}

\section{"vivemos num mundo confuso e confusamente percebido". \\ Milton Santos}

Neste artigo apresentamos uma análise centrada no corpo textual do documento Orientações Curriculares Nacionais $(\mathrm{OCN})$, sem perder de vista que os processos de identificação dentro e fora do jogo da presença/ausência (cf. DERRIDA, 1995 ; 1996) acontecem na língua(gem). E mais precisamente, no discurso, palavra de ordem nessa análise cuja raiz epistemológica está centrada nos sentidos pensados por Michel Foucault, desde a publicação da obra $A$ ordem do discurso ${ }^{2}$ e na

\footnotetext{
${ }^{2}$ A ordem do discurso é o título da célebre aula inaugural proferida por Michel Foucault no dia 2 de dezembro de 1970 quando tomava posse de uma cátedra no Collège de France, uma aula que se tornaria livro no ano seguinte, pela editora Gallimard na França. No Brasil, o livro foi publicado duas décadas mais tarde, em 1996, pelas Edições Loyola, tendo tradução de Laura Fraga de Almeida Sampaio. Nessa sua aula, o filósofo pôde mostrar ao público presente que em uma sociedade como a nossa, o discurso tem em sua ordem três tipos 128 Horizontes de Linguística Aplicada, ano 11, n. 2, jul./dez. 2012
} 
desconstrução proposta por Jacques Derrida (1995; 1996) como forma de melhor perceber a estrutura da linguagem metafísica ocidental, ou seja, desarmar tal jogo que nela se inscreve à medida que ela nutre e ordena os discursos e o pensamento, o qual não se dá sem uma certa violência simbólica (BOURDIEU, PASSERON, 2008). Portanto, é nessa tradição epistemológica que se buscava desconstruir as relações políticas do saber/poder que Michel Foucault vai enunciar a ordem do discurso, a qual é apresentada como uma produção "ao mesmo tempo controlada, selecionada, organizada e redistribuída por um número de procedimentos que têm por função conjurar seus poderes e perigos, dominar seu acontecimento aleatório, esquivar sua pesada e temível materialidade" (FOUCAULT, 1996, p. 8-9). E isso significa dizer que todo discurso incide em uma (des)ordem sob a qual se pode (des)armá-la.

Desconstruir essa ordem significa conhecer sua essência de ser e, ao mesmo tempo, colocá-la num estado de desordem porque suas leis, antes ocultadas, agora passam a ser conhecidas. Isso significa dominar tal poder-saber ou questionar sua razão de ser e sua força sobre o outro. Daí, podemos pensar que essa produção de discurso não ocorre senão por meio de uma força violenta (cf. ARAÚJO, 2011) que sempre está inscrita em sua pesada ordem, como poder que se (im)põe ao outro por meio de procedimentos elencados por Foucault (1996) em sua "aulaacontecimento", e na condição de força autorizada, que pode ser chamada aqui de violência simbólica - conforme também vemos na teoria da reprodução de Pierre Bourdieu, e em Jean-Claude Passeron (2008 [1970]) e no trabalho de Jacques Derrida (2007[1994]). Portanto, discurso, força e violência estão na ordem da estrutura $d a$ tese que será apresentada para desconstruir e/ou desarmar o corpus formado por discurso oficial ou sob a força de lei (ARAÚJO, 2011). Vale a pena lembrar que não há "nenhuma clausura taxonômica", usando as

de procedimentos de controle: externos (a interdição, a difusão e a oposição entre verdadeiro e falso); interno (o comentário, o autor e a organização das disciplinas) e regularidades de acesso (o ritual, as sociedades de discurso, as doutrinas e a apropriação social).

Horizontes de Linguística Aplicada, ano 11, n. 2, jul./dez. 2012 
palavras de Derrida (2001, p. 47), ou seja, um lugar em que se articula essa relação política com o desejo de colocar no mesmo espaço de discussão Foucault, Bourdieu e Derrida, nomes próprios que têm relação política com o pensamento crítico cuja essência é, sobretudo, política. Portanto, a análise não está fechada ao diálogo com teorias e teóricos afins.

Ao refletir sobre o discurso na qualidade de produção que ganha corpo dentro de instituições ao ser difundido por elas e nelas (cf. FOUCAULT, 1996/1997), Dominique Maingueneau (2007, p. 125) lembra que "essa imbricação de um discurso e de uma instituição é, aliás, uma ideia que tem tendência a prevalecer cada vez mais." Isso significa dizer que é dentro das instituições que os sentidos de um discurso determinado ganha corpo, porque, nesses espaços, há um sistema para transmiti-los e difundi-los, conforme afirma Foucault (1997, p. 12), "em formas pedagógicas, que ao mesmo tempo as impõe e as mantêm".

Nessa perspectiva, o discurso analisado pode ser visto como oficial na medida em que é imposto pelo governo por meio de suas práticas discursivas institucionais, ainda que nele contenha o discurso de "especialistas da ciência" para construir uma nova necessidade que, por sua vez, vai exigir uma nova (id)entidade para o professor de Português em atuação na escola básica brasileira. E com isso, confere um tom de neutralidade política ao usar a ciência como estratégia para a sua difusão e aceitação (cf. CORACINI, 2003b, 2003c), e isso tem a ver com aquilo que Michel Foucault traduz como saber-poder que institui verdades que serão difundidas por meio de práticas discursivas que vão ganhando corpo dentro das instituições (cf. FOUCAULT, 1997).

Para tanto, este artigo foi divido em três partes. A primeira é dedicada a uma reflexão acerca das histórias do ensino da Língua Portuguesa na qualidade de saber escola e fruto de uma política linguística (cf. SOARES, 2001; CALVERT, 2007; RAJAGOPALAN, 2003; ARAÚJO, 2011, ARAÚJO; FERREIRA, 2011). No segundo momento, trataremos da desconstrução do conceito de língua (im)posto

130 Horizontes de Linguística Aplicada, ano 11, n. 2, jul./dez. 2012 
pelo documento $(\mathrm{OCN})$ e, consequentemente, dos processos de identificação que tal (im)posição instaura. A última parte é consagrada à discussão acerca do conceito de cidadania, visto como palavra de ordem, nesse discurso, para a prática docente e para a formação dos sujeitos, necessária para a manutenção dos valores democráticos do Brasil, tendo sempre em mente a questão “quem somos nós professores de português?". É importante refletir sobre a posição política desse profissional diante do documento oficial que se impõe, para pensar que posição tomar diante das proposições da OCN, uma vez que não podemos perder de vista o que nos lembra Moita Lopes (2003, p. 33) que "o professor (...) está posicionando crucialmente na nova ordem mundial porque a educação linguística está no centro da vida contemporânea já que 'nada se faz sem o discurso"". Nesse sentido, precisamos da linguagem para compreender esse processo de construção identitária nesses tempos de transição de uma ordem mundial para outra, sob os efeitos da mundialização e da pós-modernidade.

O primeiro aspecto a notar, nessa construção discursiva, é a violência e o poder legítimo, a autoridade justificada (no caso em questão, na ação de um Estado que se identifica com os modelos de democracia ocidentais, buscando a manutenção do estado democrático de direito, recémestabelecido $^{3}$ com o apoio dos estudos linguísticos, dos especialistas a serviço do governo). O segundo aspecto, reforça o primeiro: encara esse discurso, não "simplesmente como aquilo que traduz as lutas ou os sistemas de dominação, mas aquilo por que, pelo que se luta, o poder do qual se quer apoderar" (FOUCAULT, 1996, p. 10). Mas o que de fato interessa é como o professor se torna sujeito em meio a essa violência simbólica que se impõe com a publicação de documentos oficiais sem a sua participação direta. Para tanto, a

\footnotetext{
${ }^{3}$ Podemos dizer que a democracia no Brasil é muito jovem, se tomarmos como ponto de partida a eleição direta para presidente da República em 1989, quando Fernando Collor de Mello chega ao Palácio do Planalto, depois de quase trinta anos de regime militar ditatorial, e também se lavarmos em consideração os duzentos anos de democracia nos EUA.
}

Horizontes de Linguística Aplicada, ano 11, n. 2, jul./dez. 2012 
abordagem discursivo-desconstrutiva será usada neste estudo. . Eis a questão sob a qual investimos para que, com essa análise, possamos refletir mais sobre a manipulação das identidades em meio à força da nova ordem mundial.

\section{As histórias do ensino da Língua Portuguesa (ou veredas de identidades)}

As histórias do ensino da Língua Portuguesa no Brasil devem ser revisitadas por duas razões: a primeira para assegurar um melhor planejamento da disciplina; a segunda, porque essas histórias apontam para o fato de que sem assegurar as condições para o ensino da língua - como saber escolar - o processo fica inviabilizado. De um lado, a ideia é evidenciar que ao longo de nossa a história, a língua sempre esteve atrelada a uma política linguística conforme Calvert (2007) e Rajagopalan (2003). De outro, é perceber que o componente histórico dessa disciplina nos ajudará a pensar com Foucault (1995) a respeito dos modos pelos quais, em nossa cultura, o professor de língua portuguesa torna-se um sujeito da língua na língua para língua no campo do saber-poder no espaço escolar, ou seja, temos um caso de objetivação do sujeito em termos foucaultianos (cf. FOUCAULT, 1995), uma vez que ele é dividido no seu interior e em relação aos outros, e "este processo o objetiva" (FOUCAULT, 1995, p.231).

Por isso evocamos o estudo realizado por Soares (2001) quando a autora traz a história da disciplina língua portuguesa na qualidade de saber/poder que surge no sistema nacional brasileiro por meio da estruturação do currículo e que tem a ver com as duas razões mencionadas anteriormente, e, que, por outro lado, tem a ver com a construção da identidade nacional. Traduzimos isso como gesto para pensarmos hoje quem somos nós professores de língua portuguesa, para tentarmos compreender essa identidade (im)posta pelas OCN a estes professores. $\mathrm{O}$ que essa história tem a ver com as políticas educacionais de hoje e os processos de identificação que elas acabam instaurando? Portanto, a reflexão que buscamos vai

132 Horizontes de Linguística Aplicada, ano 11, n. 2, jul./dez. 2012 
orientar a análise para pensarmos naquilo que foi proposto desde o título desse artigo e tem a ver com que diz Soares a respeito de compreender melhor as disciplinas língua portuguesa, mas também com o que estamos chamando de identidade para os professores de português.

Podemos ver em Linguagem e escola: uma perspectiva, outro trabalho da autora, uma abordagem para pensar com Bourdieu (2005; 2007; 2008) acerca da relação escola e linguagem, para pensarmos na questão social e política que está implícita no ensino da língua portuguesa. Dessa forma, Soares (1996, p. 79) nos lembra que "é fundamental que a escola e os professores compreendam que ensinar por meio da língua e, principalmente, ensinar a língua são tarefas não só técnicas, mas também políticas" [grifos da autora]. Portanto, o sujeitoprofessor, e, consequentemente, o sujeito-aluno não podem ser vistos como meros executores daquilo que os documentos os impõem. $\mathrm{O}$ aparecimento de conflito entre o processo de identificação e nãoidentificação em decorrência de tal imposição é latente. Por isso, convém lembrar com Coracini (2003a, p. 243), "que toda identificação com algo ou alguém ocorre na medida em que essa voz encontra eco, de modo positivo ou negativo, no interior do sujeito".

$\mathrm{Na}$ parte que trata do conhecimento de língua portuguesa, o documento OC1-EM traz o subtítulo: "Construção de novas rotas nos estudos da linguagem: caminhos que configuram a identidade da disciplina" para falar sobre as transformações dos estudos da língua e da linguagem, no Brasil e no exterior. Aparentemente, pode parecer uma tentativa para mostrar que houve avanços na história da disciplina, mas não mostra que as mudanças ocorridas passaram pela questão da política de representação ao longo dessa história, ou seja, foram motivadas com base em uma política de representação do objeto de estudo e do conceito desenvolvidos. Daí, Rajagopalan (2003, p. 76) ressalta que "muitos pecam ao não levar em consideração o fato de que em sua prática científica cotidiana os linguistas estão construindo sua identidade junto à sociedade". E isso significa dizer que todo conceito carrega em si uma identidade. 
Logo, a língua das OCN tem sua identidade, e o professor de língua portuguesa deve se identificar com ela. Vejamos como o documento apresenta a língua:

(1) “(...) a língua é uma das formas de manifestações da linguagem, é um entre os sistemas semióticos, construídos histórica e socialmente pelo homem". (BRASIL, 2006, p. 25). ${ }^{4}$

Esse conceito traz uma concepção de língua(gem) que carrega não só uma ideologia e isso implica dizer que em seu traço há identidades produzidas por linguistas que também tinham identidades, consequentemente, podemos dizer que não há neutralidade aí nem no ensino seja da língua, seja de modo geral. E nesse sentido que não podemos perder de vista, o fato apontado por Rajagopalan (2003, p. 76) de que "o discurso da linguística como um campo do saber institucionalmente consolidado e vigiado por agentes devidamente autorizados pelos membros da comunidade dos linguistas é uma prática discursiva como qualquer outra". Ou seja, o discurso da linguística também passa por uma ordem de seleção, controle de que fala Foucault (1996). Em (1) temos essa língua e não outra. A língua do documento, a língua desse discurso. A língua que se deve obedecer. A língua do jogo.

E isso terá um preço a se pagar. Para entrar nesse jogo, é preciso ter herdado uma linguagem que não é acessível a todos, ou seja, inclusive aqueles que tenham formação docente na área de Letras vão encontrar dificuldade para acessar tal língua e sua cidadania.

\footnotetext{
${ }^{4}$ No Marxismo e Filosofia da linguagem, podemos ver algo semelhante a essa ideia de língua enquanto tema, ou seja, "o tema é um sistema de signos dinâmico e complexo, que procura adaptar-se adequadamente às condições de um dado momento da evolução".
}

134 Horizontes de Linguística Aplicada, ano 11, n. 2, jul./dez. 2012 


\section{Sobre a concepção de língua(gem)}

A concepção de língua(gem) das OCN assumida é a interacional. Logo, a forma de língua (im)posta é aquela advinda de Bakhtin (1997) como podemos ver em (2) no formato de nota de rodapé do documento - o que já acontece nos PCN de Língua Portuguesa (cf. ARAÚJO, 2011;ARAÚJO;FERREIRA， 2011), e, cujas referências bibliográficas vão confirmar a pretensão de tornar uma prática discursiva tanto na escola fundamental quanto da escola média. Vejamos nos excertos (2) e (3) a seguir sobre o que o documento chama de noção de prática de linguagem em sua abordagem interacionista, ou seja, como ela se inscreve:

(2) Está-se referindo aqui tanto à contribuição de estudos desenvolvidos por essa vertente no escopo da Linguística, os quais envolvem estudiosos como Hymes, e na Filosofia da Linguagem, como Bakhtin, na Etnometodologia e Sociologia, como Goffman, na Psicologia, como Bronckart e na educação, como Schneuwly, quanto aos que se encontram no âmbito da Psicologia do Desenvolvimento, como é o caso de Vygotsky e seus seguidores (BRASIL, 2006, p. 23).

(3) noção de prática de linguagem aqui adotada compreende o processo de inserção dos sujeitos nas práticas sociais, que têm a linguagem como mediadora das ações, tendo em vista os propósitos em jogo. Isso significa que as práticas de linguagem só podem ser pensadas em termos dos espaços sociais (públicos ou privados) em que se configuram, a partir das finalidades que as motivam e dos lugares sociais nelas instaurados (BRASIL, 2006, p.30).

Ainda que esta concepção de língua(gem) opere em torno de interacionismo dialógico que se diz bakhtiniano ${ }^{5}$, o tom

\footnotetext{
${ }^{5} \mathrm{O}$ dialogismo, em termos bakhtinianos, pode ser visto, grosso modo, como a interação social de indivíduos através da palavra. Já o termo "diálogo, no Horizontes de Linguística Aplicada, ano 11, n. 2, jul./dez. 2012 
"assertivo e informativo" (cf. CORACINI, 2007), acaba pondo em risco o sentido de ser das concepções advindas do pensador russo. Ou seria uma questão de tradução em termos derridianos? São várias questões sem respostas quando buscamos encontrálas nas OCN (BRASIL, 2006).

\section{O objeto de ensino: o fora e o dentro da língua}

A língua na qualidade de saber escolar, inserida, portanto, no currículo, não pode ser vista apenas como objeto de estudo, mas como algo inscrito no campo das relações de saber/poder de que fala Foucault na medida em que por meio da língua, os discursos são tecidos, mas sempre sob a força da ordem social, ou da política de relação que fala Derrida (1996) diante de um face a face que nem sempre é pacífico. Daí, não podemos nos esquecer de que no ensino, tudo é ideológico, e, isso implica dizer que pensar neste campo de saber/poder implica pensá-lo na condição de estrutura de língua(gem) dentro da linguagem metafísica ocidental, lugar de construção e desconstrução de sistemas de representação (cf. ARAÚJO; FERREIRA, 2011, p.97), do qual "a educação seria apenas um subsistema” (FREIRE; HORTON, 2009, p. 194). É a partir daí que vamos analisar o papel da disciplina, a qual está inscrita nesse jogo. Tomemos os excertos a seguir para tanto:

(4) o papel da disciplina Língua Portuguesa é possibilitar, por procedimentos sistemáticos, o desenvolvimento das ações de produção de linguagem em diferentes situações de interação. (BRASIL, 2006, p. 27).

sentido estrito do termo, não constitui, é claro, senão uma das formas, é verdade que das mais importantes, da interação verbal. Mas pode-se compreender a palavra "diálogo" num sentido amplo, isto é, não apenas como a comunicação em voz alta, de pessoas colocadas face a face, mas toda comunicação verbal, de qualquer tipo que seja”. (Cf. BAKHTIN [VOLOSHINOV], p.125)

136 Horizontes de Linguística Aplicada, ano 11, n. 2, jul./dez. 2012 
(5) (...) tomar a ação de ensinar como uma ação política reporta à ideia de que conhecimento é o produto de um trabalho social e sua construção é fruto de investigação e (re)elaboração com cooperação dos outros. (BRASIL, 2006, p.36).

No excerto (4), podemos perceber como ele está coerentemente ligado à "reificação" da língua à medida que o professor deve se identificar e obedecer tal ordem que impõe para si uma visão de língua, bem como uma prática para lidar com essa língua. A reificação ${ }^{6}$ da língua nada mais é do que a investidura de superpoderes dado a ela pelo documento, o tom assertivo é claro quando afirma que "o papel da disciplina Língua Portuguesa é (...)". Eis a força de lei desse discurso. Eis um traço da identidade para o professor do Ensino Médio. Mas será que isso é possível, já que em boa parte das escolas encontramos professores sem formação acadêmica, além dos processos de desvalorização da profissão? Já no excerto (5), destacam-se, aos nossos olhos, os sintagmas "ação de ensinar" e "ação política" os quais são apresentados como algo da mesma ordem, sem os conflitos do dia a dia que surgem em função das diferenças existentes na formação de cada indivíduo, ou seja, os processos de identificação não são os mesmos para todos os indivíduos, ainda mais numa sociedade como a nossa cheia de contrastes de ordem social, cultural e econômica. A questão é como gerenciar e saber lidar com o outro em sua diferença para que o professor possa ser mediador dessa ação em meio a universo marcado pela violência simbólica. De fato, a ação de ensinar vista como ação política tem a ver com a ideia de dialogismo em Bakhtin (1997) e com os ensinamentos do grande educador brasileiro Paulo Freire (FREIRE, 1996; FREIRE; HORTON, 2009). Mas será que os cursos de Letras do país tem atentado para essa nova orientação? Há muita coisa por fazer, ainda que as OCN deixam

\footnotetext{
${ }^{6}$ Em língua alemã se diz: Verdinglichung, literalmente: "transformar uma ideia a em uma coisa" (do latim res: "coisa"; ou Versachlichung, literalmente "objetificação". Esse termo é bastante empregado no Marxismo ao lado de alienação (cf. SARUP, 1986).
}

Horizontes de Linguística Aplicada, ano 11, n. 2, jul./dez. 2012 
claro que o governo está fazendo sua parte na forma de carta endereçada ao professor, conforme podemos ver a seguir:

Para garantir a democratização do acesso e as condições de permanência na escola durante as três etapas da educação básica - educação infantil, ensino fundamental e médio -, om governo federal elaborou a proposta do Fundeb (Fundo de Manutenção e Desenvolvimento da Educação Básica e de Valorização dos Profissionais da Educação). A Proposta de Emenda à Constituição (PEC) do Fundeb foi construída com a participação dos dirigentes das redes de ensino e de diversos segmentos da sociedade. (...) Entre as várias ações de fortalecimento do ensino médio destacam-se o Prodeb (Programa de Equalização das Oportunidades de Acesso à Educação Básica) e a implementação do PNLEM (Programa Nacional do Livro do Ensino Médio). A Secretaria de Educação Básica do MEC passou a publicar ainda livros para o professor, a fim de apoiar o trabalho científico e pedagógico do docente em sala de aula (BRASIL, 2006, p. 5).

Claro que não podemos negar essas conquistas no campo da educação, mas de uma maneira bem sensível porque o processo está em andamento. Logo, estas ações serão não sentidas em curto prazo, sobretudo, porque vivemos num país de dimensão continental onde as desigualdades tanto sociais quanto regionais ainda fazem parte da nossa realidade, sem falar nas questões de acessibilidade aos bens culturais produzidos pela indústria cultura centralizada no eixo Rio-São Paulo.

A criação das OCN é parte dessas ações do governo, desse jogo político que vai impondo tanto uma identidade linguística quanto uma identidade para o professor de língua portuguesa. Isso é política linguística de estado. $\mathrm{Na}$ seção a seguir, trataremos mais especificamente das competências, não só linguística que se exige do aluno e do professor, mas da questão trazida por Rajagopalan (2003) de que as teorias linguísticas também são veículos de ideologias, e que esse

138 Horizontes de Linguística Aplicada, ano 11, n. 2, jul./dez. 2012 
conceito-encruzilhada não está pacificado na linguística e muito menos nos documento, seu é emprego é regular.

Podemos dizer que nas OCN (BRASIL, 2006), o termo competência não aparece com tanta frequência quanto nos PCN de Língua Portuguesa, mas na introdução do documento, ele é apresentado como uma espécie de interdiscurso tanto da LDBN (Lei $\mathrm{n}^{\circ}$ 9394/96) quanto dos PCN, conforme podemos ver no excerto seguinte:

(6) $\mathrm{O}$ primeiro diz respeito às finalidades atribuídas ao ensino médio: o aprimoramento do educando como ser humano, sua formação ética, desenvolvimento de sua autonomia intelectual e de seu pensamento crítico, sua preparação para o mundo do trabalho e o desenvolvimento de competências para continuar seu aprendizado (Art. 35 apud BRASIL, 2006, p. 7).

Essa competência, presente em (6), parece divergir daquela dos PCN de língua portuguesa (Ensino Fundamental), ora vista como competência linguística, ora como competência discursiva, ou será que a competência linguística estaria inserida nessas outras para continuar o aprendizado dos alunos? Mas antes delas, surge uma mais urgente: "afinal, o que tem significado a noção de competência no terreno dos estudos da Linguagem? O que ela tem conseguido explicar a respeito da linguagem, suas circunstâncias de uso e de seu modo de existir?" (MORATO, 2008, p. 39). Nos PCN de língua portuguesa, ela aparece com essas duas caras (cf. ARAÚJO, 2011; ARAÚJO; FERREIRA, 2011). Como se sabe, essa discussão pretende tratar de algo que é dado como dominado ou que deva ser dominado pelo menos a princípio pelo professor de língua portuguesa. Essa falta de clareza também é indício daquilo que estamos chamando com Bourdieu e Passeron (2007) de violência simbólica contra o professor, mais precisamente da sua forma de sujeição. Vejamos o seguinte excerto:

(7) (...) a definição do que vai se propor como objeto de ensino, a rigor, é uma ação de natureza pedagógica e 
sobretudo política, voltada para a criação de situações de ensino que propiciem a construção de conhecimentos que ressalte de uma atividade de busca por parte do próprio aluno, fundada em situações de aprendizagem significativa, a partir das indicações e orientações fornecidas pelo professor. (BRASIL, 2006, p. 35 [grifo meu]).

Estamos diante de mais uma encruzilhada: linguagem e seu domínio. Domínio nada certo ou óbvio no campo dos estudos linguísticos de algo tão (con)fuso e difuso de uma área do conhecimento que "fez questão de se projetar como uma ciência com todo rigor da palavra" (RAJAGOPALAN, 2003, p. 24) , mas continuamos perguntando: $O$ que é mesmo linguagem? Todos nós sabemos que ela existe e nos faz existir, mas como conceituar algo que é nosso e não temos controle? Aqui vale lembrarmo-nos de Chomsky (2005), que talvez ele já tenha perdido a conta das conferências mundo a fora, inclusive aqui no Brasil, para explicar o que seja de fato a linguagem. Ainda sim, muita gente não se contenta como os argumentos chomskianos de que a linguagem é como, senão é mesmo, um órgão do corpo humano. Uma faculdade inata do ser humano, própria do homem. Se buscarmos uma resposta em Bakhtin, não será a mesma. Do mesmo modo, em Saussure (mais precisamente em seu Cours de Linguistique Générale). Talvez apenas essa falta de consenso mostre a complexidade da questão tal qual a própria complexidade do ser e de ser homem em todas as suas dimensões.

Conforme vimos anteriormente, o conceito contido no excerto (1) não está isento de ideologias nem de uma identidade, vista como processo (cf. DERRIDA, 1996; CORACINI, 2003a; 2003b; 2003c). Ele traz consigo o rastro da nova ordem em pensar a mundialização quando se trata de língua não é pensar a padronização em escala mundial, mas, ao contrário, a possibilidade de apreender a diversidade, a multiplicidade de sentidos que aí podem existir (ORLANDI, 2009, p. 159). Nessa definição de língua dada em (1), a dimensão histórica e cultural que permite uma transformação das/nas velhas estruturas dos

140 Horizontes de Linguística Aplicada, ano 11, n. 2, jul./dez. 2012 
Estados e das comunidades nacionais, num projeto de "transnacionalização da vida econômica e cultural", como argumenta Robins (1997). Dessa forma, a língua, como lugar de identidades, contribui para formar "consumidores globais" através do jogo de linguagem da mundialização. Por isso é preciso mudar não só a concepção de língua, tornando-a comum em todo o sistema, mas também a própria concepção de currículo que o documento deixa bem claro qual é a concepção que o professor de língua portuguesa deve se identificar, ou seja,

(8) O currículo é a expressão dinâmica do conceito que a escola e o sistema de ensino têm sobre o desenvolvimento dos seus alunos e que se propõe a realizar com e para eles. Portanto, qualquer orientação que se apresente não pode chegar à equipe docente como prescrição quanto ao trabalho a ser feito. (BRASIL, 2006, p.9).

Essa quase advertência reaparecerá na introdução da seção dedicada à língua portuguesa, como podemos observar no excerto a seguir:

(9) o professor deve ter em mente que a proposição de Orientações Curriculares Nacionais de Língua Portuguesa para o ensino médio é tarefa que se realiza por meio da discussão e da defesa de uma concepção de ensino orientadora tanto da emergência de objetos de ensino/estudo quanto das abordagens a serem adotadas nessa tarefa (BRASIL, 2006, p. 17).

O tom assertivo com que a concepção de currículo em (9) é apresentada tem força de Lei porque está sob força de lei. Aí não há lugar para outras concepções, pois a escolha já foi feita, não há espaço para discussão. Alguém já fez para o professor, além disso, cumpre destacar aí o sintagma "não pode" o que diz o que pode e o que não fazer. Isso não é uma prescrição? Essa afirmação sobre currículo parece colocar uma pedra em cima de uma discussão que vem sendo feita hoje sobre o que é currículo, ignorando todo um percurso histórico da Horizontes de Linguística Aplicada, ano 11, n. 2, jul./dez. 2012 
evolução de tal conceito, deixando claro que este é o currículo em sua concepção adotado pelo documento. Em (9), esse tom de autoridade que tudo sabe e tudo pode quando diz: "o professor deve ter (...)", deixado demarcado, ao mesmo tempo, o que ele não deve ter; o que de certa forma tira do professor o seu status de intelectual, de autoridade. Agora o professor parece não ter razão já que volta a seu estado de menoridade de que fala Kant (1784 [2011])) em seu texto "Was ist Aufklärung?" (O que é o esclarecimento?) quando o filósofo alemão vai discutir a passagem do estado de menoridade para o estado da maioridade com o advento do iluminismo e nos faz refletir acerca da liberdade e mesmo da subjetividade. É daí que Foucault (1995) vai traduzir a questão para o “quem somos nós?", questão cara à nossa análise porque com ela buscamos pensar nessa identidade imposta sob a força de lei. Mais adiante discutiremos sobre o sujeito e o processo de subjetividade que se instaura com essa imposição. E ele se dá nas OCN com base em uma série de conceitos ou saber que o bom professor de língua portuguesa deve conhecer para tornar sua prática mais adequada ao momento atual que vivemos.

\section{Sujeito da linguagem ou sujeito do ensino (variáveis do ensino-aprendizagem)}

A língua (im)posta neste documento tem seu(s) sentido(s) forjado (s) de fora de si e passa a ter um lugar de destaque na política linguística do país (e/ou educacional) através do discurso contido no documento em análise. Parece claro que objetivo dessa mudança é promover a igualdade entre os sujeitos, os quais, nas relações com a palavra, precisam negociar os sentidos entre si, e isso só é possível se houver uma relação dialógica, em que os sujeitos precisam estar em posição de igualdade, ao menos de identidade para fazer acontecer o mercado global. Tal igualdade linguística parece ser o motivo para se pensar no exercício da cidadania como ação imbricada com os atos da língua(gem), nesses tempos em se constata o "fenômeno que vem sendo chamado de "transnacionalização" e,

142 Horizontes de Linguística Aplicada, ano 11, n. 2, jul./dez. 2012 
com efeito, a "desterritorialização" das pessoas, a mestiçagens das línguas em novas práticas identitárias (cf. RAJAGOPALAN, 2003). Daí, a questão do “quem somos nós?" em Foucault (1995) nos convida a pensar o presente, o agora, na condição de sujeitos com uma historicidade que nos atravessa e constitui, para pensarmos "Quem são os bons professores?" "Quem são os bons alunos?". Como toda questão, essas têm seus lados contrários: "quem são os maus professores?" e "os maus alunos, maus dirigentes?" E isso tem a ver com o que fala Coracini quando diz "que toda identificação com algo ou alguém ocorre na medida em que essa voz encontra eco, de modo positivo ou negativo, no interior do sujeito" (CORACINI, 2003a, p. 243), conforme vimos anteriormente.

A história conforme Foucault (1950 nos mostra que a questão da subjetividade ganhou um corpo próprio na modernidade. Nessa pós-modernidade, sua condição de ser é subvertê-la para que um novo corpo de subjetividade apareça. Logo a velha cede lugar ao não-lugar da nova ordem, "consequência imediata do rompimento das barreiras que, até pouco tempo atrás, pareciam intransponíveis e serviam de impedimento a qualquer forma de aproximação entre os povos, a não ser com propósitos nada amigáveis" (RAJAGOPALAN, 2003, p. 57). No entanto, as políticas linguísticas ainda não romperam totalmente com os laços do imperialismo linguístico do século XIX (cf. RAJAGOPALAN, 2003). Ainda, sujeitos e língua(s) se configuram mutuamente em meio à ilusão das questões de fixação da(s) língua(s) e das identidades na velha e na nova ordem mundial, no desejo de uma igualdade de um devir a ser, assim como a ideia de cidadania que se veicula hoje por meio da mundialização em sua forma mais perversa de violência simbólica que poderíamos chamá-la de "Globalitarismo", tomando o termo emprestado de Milton Santos (2008). Essa ideia de competência, em dar competência está muito ligada à ideia de igualdade. Para Signorini (2008), tal ideia está presente em políticas de Estados republicanos e liberais, portanto, 
essa igualdade é algo a ser conquistado individualmente por cada falante por meio do letramento escolar: por meio da escolarização, todos podem apropriar-se das formas e funções valorizadas pelo Estado e demais instituições e, assim, conquistar a igualdade de condições na comunicação social. Mas como esse é um objetivo sempre postergado para a maioria, inclusive os escolarizados, acaba funcionando como uma espécie de álibi que vai sempre justificar a diferença congênita irredutível que desqualifica a maioria dos falantes enquanto falantes autorizados e, consequentemente, enquanto interlocutores, agentes, cidadão etc. (SIGNORINI, 2008, p. 172).

Nesse sentido, sobre a doutrina da igualdade liberal, vimos, anteriormente, em Nietzsche (2006, p. 98), que "não há veneno mais venenoso: pois ela parece ser pregação da própria justiça... 'Igualdade aos iguais, desigualdade aos desiguais'- isto seria o verdadeiro discurso da justiça: e, o que daí se segue: 'Nunca tornar igual o desigual'". Seria a igualdade apenas um efeito de linguagem usado pelo Estado?

O documento apresenta o sujeito-aluno e o sujeitoprofessor como variáveis do ensino-aprendizagem ao lado do conhecimento linguístico com base na noção de língua, anteriormente, vista. Cada um com seu papel e função no processo do ensino-aprendizagem em L1 na escola. Mas papéis e posições diferentes que formam um sistema hierárquico. É possível pensar em igualdade na democracia em uma relação como essa? Se "democracia significa, minimamente, igualdade"; qual o sentido dela dentro do ambiente escolar? Qual o lugar dos sujeitos nesse discurso produzido na democracia para fomentar cidadania com base em ações no/do ambiente escolar? Vejamos como o documento define isso, ou melhor, a posição e a função dos sujeitos e do "objeto" nos excertos seguintes:

(10) [pode-se dizer que] as ações realizadas na disciplina Língua Portuguesa, no contexto do ensino médio, devem propiciar ao aluno o refinamento de habilidades de

144 Horizontes de Linguística Aplicada, ano 11, n. 2, jul./dez. 2012 
leitura e de escrita, de fala e de escuta (BRASIL, 2006, p. 18).

(11) pode-se dizer que o mais geral deles é o de que é pela linguagem que o homem se constitui sujeito. (BRASIL, 2006, p. 23)

(12) devem ser também considerados os conhecimentos sobre as formas pelas quais se estabelecem relações entre sujeitos sociais e, ainda, conhecimentos sobre os modos de conceber o mundo, ligados aos grupos sociais dos quais participamos ou com os quais interagimos (idem, ibidem, p. 26).

Nesses excertos fica claro qual é o lugar de cada um na escola, isto é, nessa relação fica claro quem tem o poder para organizar e mediar. Dito de outra forma, no espaço escolar, "o professor é institucional e idealmente aquele que possui o saber e está na escola para ensinar, o aluno é aquele que não sabe e está na escola para aprender" (ORLANDI, 2003, p. 31).

Podemos dizer que o conceito de língua, de certa forma, surge como um desdobramento daquele que aparece nos PCN de Língua Portuguesa na modalidade do ensino fundamental (cf. ARAÚJO; FERREIRA, 2011). Vale a pena lembrar que as OCN nascem no governo do presidente Luiz Inácio Lula da Silva, e os PCN, no governo da social democracia de FHC. Eis as condições de produção desses dois discursos: lugares de uma ordem ideológica bem diferente uma da outra, mas que usam a ciência como forma de tornar neutro o discurso nesses documentos. Elas também estão ligadas ao movimento da mundialização que vem impondo saber pelo consumo das línguas. Nisso podemos ver também uma medida de política linguística de Estado cujo momento específico é o de tornar a língua portuguesa, hoje, lugar de saber/poder no cenário que está sob a ordem da mundialização. Portanto, a reconfiguração de sua constituição como saber metalinguístico se iniciou no fim dos anos 1980, para inserir o Brasil política e economicamente no cenário mundial por meio de um processo de gramatização pelo qual o português do Brasil se constitui em língua transnacional Horizontes de Linguística Aplicada, ano 11, n. 2, jul./dez. 2012 
com a institucionalização e instrumentação do Português Língua Estrangeira (PLE) como nova área de conhecimento (DINIS; ZOPPI-FONTANA, 2008, p. 89-90).

Nesta rede discursiva, tecida nas OCN para o Ensino Médio, a definição de "língua(gem)" aparece como a ponta do fio (conceito-chave) que estabelece uma relação política direta com as palavras democracia, cidadania, autonomia, competência (discursiva), inclusão, mediação, participação. A estrutura dessa rede pode ser mais bem percebida com base no conceito de interdiscurso, uma ferramenta indispensável em uma abordagem discursivo-desconstrutiva tal qual propõe Coracini (cf. 2003a, 2003b, 2007), a qual usamos como suporte para a análise. Ancorados nessa rede que iremos desconstruir as representações dessa identidade para o professor de língua portuguesa na modalidade do ensino médio.

Podemos dizer, então, que o interdiscurso está sob o domínio do que pode ser dito território da heterogeneidade constitutivo do discurso que resulta do entrecruzamento de vários outros discursos, território da heterogeneidade constitutiva (AUTHIER-REVUZ, 1998 apud CORACINI, 2003a, p. 193) ou ainda, numa outra perspectiva, podemos ver em Orlandi (2007, p. 31) que "o interdiscurso disponibiliza dizeres que afetam o modo como o sujeito significa em uma situação discursiva dada". Portanto, ele pode ser entendido como todo conjunto de formulações feitas e já esquecidas que determinam o que dizemos. Para que as palavras tenham sentido é preciso que elas já façam sentido e isto é efeito do interdiscurso (Idem, ibidem). Dessa forma, podemos dizer que a memória do discurso em análise, ou o interdiscurso, faz parte da produção deste discurso, na medida em que "retorna sob a forma de pré-construído, o já-dito que está na base do dizível, sustentando cada tomada de palavra". E isso nos permite identificar sua historicidade, sua significância, percebendo seus compromissos políticos e ideológicos. Como memória do dizer, o interdiscurso é que possibilita, ao analista, perceber no discurso uma identidade política/ideológica.

146 Horizontes de Linguística Aplicada, ano 11, n. 2, jul./dez. 2012 
A filiação de um discurso está no interdiscurso, o qual permite, na perspectiva histórica, compreender sua localização em uma determinada formação discursiva, ou ao menos, sua fronteira - marcada pela heterogeneidade dos sentidos da linguagem e da ideologia. Consoante Orlandi (2001, p. 100), "a ideologia não é, como se sabe consciente. Ela é efeito da relação do sujeito com a língua e com a história em sua necessidade conjunta". Dessa forma, podemos dizer que nesses tempos de crises, o conceito de cidadania parece ter sido mergulhado na penumbra do discurso da globalização que "astutamente oculta ou nela busca penumbrar a reedição intensificada ao máximo que modifica, da medonha malvadez com que o capitalismo aparece na História" (FREIRE, 1996, p.127-128). E esse fato nos leva à questão: “o que é mesmo cidadania?”, uma vez que ela se apresenta como algo dado, pronto, acabado e, ao mesmo tempo, indispensável para a prática do ensino da língua portuguesa. Por outro lado, tal questão nos leva a uma "contrapalavra" ou "contra-questão" do que não é cidadania. Se não está claro qual o sentido dado à cidadania, sua imposição assume a forma mais perversa de violência simbólica. E suas consequências têm a ver com a medonha malvadez de que fala Feire (1996), conforme vimos anteriormente.

Iniciemos a discussão sobre o que seja cidadania, fundamentados em Covre (2001), uma vez que a autora busca compreender a palavra com base em sua origem etimológica. Para ela, o termo "cidadania" surge do latim civitas, "cidade" para designar um estatuto de pertencimento de um indivíduo a uma comunidade politicamente articulada e que lhe atribui um conjunto de direitos e obrigações. Dessa forma, no dizer de Araújo (2011a), "predominantemente, quando se fala em cidadania compreende-se a condição do ser social como participante de certa sociedade firmada através de um pacto que o torna sujeito de direitos e deveres". E nesse caso, podemos falar em cidadão, noção já presente na Grécia Antiga, quando temos em Aristóteles (RUSS, 1994, p. 35) a seguinte afirmação: "o que constitui [...] o cidadão, sua qualidade verdadeiramente característica, é o direito de sufrágio nas Assembleias e de 
participação no exercício do poder". No sentido restrito ou primeiro de cidadão, ao que parece, mudou-se muito pouco de lá para cá, se comparado ao sentido dado por Spinoza (2010) séculos depois, em que cidadão parece como uma espécie de déjà $d u$ (já-dito) aristotélico: "chamamos cidadão aos homens considerados como desfrutando de todas as vantagens que a Cidade proporciona em virtude do direito civil", (idem, ibidem). Então, ao que nos parece, os termos cidadania e cidadão, estão ligados diretamente ao regime democrático. São próprios dos Estados ou cidades que proporcionam tal direito civil.

Há cerca de quatro séculos, essa atividade social chamada instruir vem-se construindo, progressivamente, numa dimensão integrante da cultura da modernidade, sem falar de seus importantes impactos sobre a economia e os demais aspectos da vida coletiva, sobretudo políticos, tanto é verdade que o conceito de cidadania é impensável sem o de instrução. (LESSARD; TARDIF, 2005, p.7).

Em suma: no campo da educação, a cidadania é uma condição tanto para a modernidade (em desordem) quanto para pós-modernidade (emergente) por meio dos discursos que fazem parte das políticas linguísticas de Estado. Os excertos, a seguir, mostram essa ênfase dada ao termo cidadania. Vejamos:

(13) A qualidade da escola é condição essencial de inclusão e democratização das oportunidades no Brasil, e o desafio de oferecer uma educação básica de qualidade para a inserção do aluno, o desenvolvimento do país e a consolidação da cidadania é tarefa de todos.

(14) o ensino médio deve atuar de forma que garanta ao estudante a preparação básica para o prosseguimento dos estudos, para a inserção no mundo do trabalho e para o exercício cotidiano da cidadania, em sintonia com as necessidades político-sociais de seu tempo.

148 Horizontes de Linguística Aplicada, ano 11, n. 2, jul./dez. 2012 
Conforme verificamos em (13) e (14), a ideia de cidadania parece algo dado, acabado, livre dos conflitos de linguagem de uma nova ordem mundial que se instala, sobretudo, ao impor uma nova prática discursiva em que a questão do exercício da cidadania tem um valor, mas esvaziado de sentidos.

\section{Considerações finais}

Conforme vimos, "os sentidos e os sujeitos se constituem em processos em que há transferências, jogos simbólicos dos quais não temos o controle e nos quais o equívoco - o trabalho da ideologia e do inconsciente - estão largamente presentes" (ORLANDI, 2007). E diante de toda a problemática que a nova ordem vem implementando, é crucial que os professores não percam de vista o fato de que fazem parte desse processo, ou melhor, dos processos sociais, políticos, econômicos, tecnológicos e culturais que estamos vivenciando. Nesse sentido, alerta Moita Lopes (2003, p. 31) que "sem a compreensão do que se vive, não há vida política".

Dessa forma, caberá a nós, tornar claros tais processos no corpus em questão, ou seja, descrever a estrutura (a língua) e o seu acontecimento (o discurso) no corpus e, perguntarmos sempre: quem somos nós professores de língua portuguesa hoje? Como forma de se posicionar diante daquilo que está sendo (im)posto para o professor. Não podemos perder de vista que este discurso é veículo de um saber e ao mesmo tempo expressão do poder de quem o (im)põe e de quem o produz. Para Barbosa (2000, p. 150),

nenhum dos documentos oficiais colocados como referências curriculares de estados e municípios pode ser transposto para a sala de aula, o que feriria a natureza de tais documentos e seria contraditório com alguns princípios orientadores da prática pedagógica nestes assumidos, por exemplo, o princípio de respeito à pluralidade de realidades culturais.

Horizontes de Linguística Aplicada, ano 11, n. 2, jul./dez. 2012 
O que nos chama a atenção na observação de Barbosa (ibidem) é a ingenuidade de achar que, em nome do respeito à pluralidade cultural, documentos como os OCN (cf. BRASIL, 2006) possam dispor de tal natureza, a de respeitar tais preceitos. É essa ilusão que atacamos aqui, a ilusão de respeitar impondo referências, uma vez que elas não são apenas referências, pelo contrário, têm a força das leis oficiais e com tal força carregam a coerção veiculada nas práticas discursivas institucionalizadas. Uma força que se alimenta da medonha malvadeza do Globalitarismo que, "de fato, para grande maior parte [sic] da humanidade, a globalização está se impondo como uma fábrica de perversidade" (ibidem, p.19). Uma força é a própria violência simbólica contra o professor em sua subjetividade docente, atingida por um processo de identificação que os torna objeto.

Outra ilusão é a de que adotar uma concepção de linguagem supostamente bakhtiniana para o ensino de português tornaria tal documento $(\mathrm{OCN})$ politicamente dialógico. Ou seja, ao tratar de dialogismo proposto por Bakhtin e ao conceber a língua, conforme vimos anteriormente, como "sistema de signos específicos, histórico e social, que possibilita a homens e mulheres significar o mundo e a sociedade"; esse documento seria ideal para formar cidadãos. No entanto, o tom do documento é um tom que tenta homogeneizar os sentidos e as práticas discursivas a partir de uma rede discurso que tem a língua e a cidadania como centro, mas, apresentados de uma forma pacifica como se estivessem livres dos conflitos e das ideologias que trazem consigo em seus rastros de palavras (e sua contrapalavra), o que prejudica o caráter reflexivo da teoria proposta pelo pesquisador russo, i.e., a reflexão fica suspensa porque é imposta como lei, é como um remédio indicado pelo médico ao paciente, que obedece prontamente a indicação sem questionar sua autoridade de médico, numa relação que um sujeito tem mais poder que o outro. A língua e a cidadania estão aí sob um estado de reificação. Enquanto o professor é tratado como objeto manipulável.

De acordo com Soares (2001), o processo de organização do currículo sempre foi uma questão política à

150 Horizontes de Linguística Aplicada, ano 11, n. 2, jul./dez. 2012 
medida que incide em instaurar um saber poder que (im)põe, ao mesmo tempo, processos de identificação, resistências, lutas e conflitos. Por outro lado, se se quer promover a participação dos sujeitos, há de se pensar numa política de relação de que fala Derrida (1996), ou melhor dizendo, numa relação política, visto que "quanto mais as pessoas participarem do processo de sua própria educação, maior será sua participação no processo de definir que tipo de produção produzir, e para que e por que" (FREIRE, 2009, p.149). Portanto, "maior será também sua participação no seu próprio desenvolvimento" (idem, ibidem). E isso será mesmo violento na medida em que os indivíduos se tornam agentes ativos do processo que se quer instaurar diminuindo a violência simbólica latente nem jogo de discurso, saber/poder.

A crítica que tentamos tecer neste artigo tem na maior parte esta preocupação: a falta de participação das comunidades escolares do país na discussão e na produção desses dois documentos políticos, mas que de certa forma se esconde na falsa neutralidade política de suas comissões formadas por especialistas (experts), diria Lyotard (2000), ou Coracini (2007). A especialidade nunca conferiu isenção política a ninguém, visto que as disciplinas acadêmicas - como nos ensina Rajagopalan (2003) - se formam com base em uma identidade, e isso significa dizer na tradução que fazemos de Rajagopalan (ibidem) que enquanto construção social de linguagem é política, em termos do que Paulo Freire chama de política. Nesse sentido lembramos do discurso de posse da presente Dilma Rousseff "só existirá ensino de qualidade se o professor e a professora forem tratados como as verdadeiras autoridades da educação, com formação continuada, remuneração adequada e sólido compromisso com a educação das crianças e jovens", esperando com isso que haja mais diálogo com os professores no que diz respeito às questões ligadas ao campo da Educação. Mas isso só acontecerá se constantemente nos posicionarmos diante das imposições ao nos perguntarmos sempre "quem somos nós"?”. 


\section{Referências}

AMARAL, Ana Lúcia. A adjetivação do professor: uma identidade perdida? In: AMARAL, Ana Lúcia; VEIGA, Ilma. P. A. (Org.). Formação de professores: políticas e debates. Campinas, SP: Papirus, 2002.

ARAUJO. Alex P. A ordem do discurso e a violência simbólica nos PCN e nas Orientações: em questão a identidade do professor de português construída sob a força de lei. Dissertação (Mestrado em Letras: Linguagens e Representações) - DLA, Universidade Estadual de Santa Cruz, Ilhéus-BA, 2011.

ARAÚJO, Alex P.; FERREIRA, Élida. P. A identidade em parâmetros curriculares: em questão a subjetividade do professor de português. Revista Eletrônica de Educação. São Carlos, SP: UFSCar, v. 5, n. 2, p.96-123, nov. 2011. Disponível em< http://www.reveduc.ufscar.br>. Acesso em: 20 dez. 2011

BAKHTIN, Mikhail. [VOLOSHINOV, V. V.] Marxismo $e$ filosofia da linguagem. Trad. Michel Lahud e Yara F. Vieira. 8 ed. São Paulo: Hucitec, 1997.

BARBOSA, Jacqueline. P. Do professor suposto pelos PCNS ao professor real de língua portuguesa: são os PCNS praticáveis. In: ROJO, Roxane.(Org.). A prática de linguagem em sala de aula: praticando os PCNs. Campinas, SP: Mercado de Letras, 2000.

BOURDIEU, Pierre. A economia das trocas simbólicas. Tradução de Sergio Miceli et al. 6 ed. São Paulo: Perspectiva, 2005.

O poder simbólico. Tradução Fernando Tomaz (português de Portugal). 11 ed. Rio de Janeiro: Bertrand Brasil, 2007.

.; PASSERON, Jean-Claude. A reprodução: elementos para uma teoria do sistema de ensino. Tradução de Reynaldo

152 Horizontes de Linguística Aplicada, ano 11, n. 2, jul./dez. 2012 
Barão; revisão de Pedro B. Garcia e Ana Maria Beata. Petrópolis, RJ: Vozes, 2008.

BRASIL. Secretaria de Educação Fundamental. Parâmetros curriculares nacionais: terceiro e quarto ciclos do ensino fundamental: língua portuguesa. Brasília: MEC/SEF, 1998.

Secretaria de Educação Básica. Orientações curriculares para o ensino médio: linguagens, códigos e suas tecnologias. Brasília: MEC, Secretaria de Educação Básica, 2006.

CALVERT, Louis-Jean. As políticas linguísticas. Tradução de Isabel de Oliveira Duarte, Jonas Tenfen e Marcos Bagno. São Paulo: Parábola Editorial, 2007.

CHOMSKY, Noam. Novos horizontes no estudo da Linguagem $e$ da mente. Tradução de Marco Antônio Sant'Ana. São Paulo: UNESP, 2005.

COELHO, Maria Inês M. Formação e construção de identidade de professores e a cultura de gerencialismo e performatividade do estado. Disponível em <http://www.isecure.com.br/anpae/297.pdf >. Acesso em: 12 mai. 2009.

CORACINI, Maria José. Subjetividade e identidade do (a) professor (a) de português. In: (Org.). Identidade $e$ discurso: (des) construindo subjetividades. Campinas, SP: Editora da UNICAMP; Chapecó: Argos Editora Universitária, 2003a.

- O discurso da linguística aplicada e a questão da identidade: entre a modernidade e a pós-modernidade. In: BERTOLD, Ernesto. S.; CORACINI, Maria José. (Org.). O desejo da teoria e a contingência da prática: discursos sobre $n a$ sala de aula. Campinas, SP: Mercado de Letras, 2003b. 
- O olhar da ciência e a construção da identidade do professor de línguas. In: BERTOLD, Ernesto. S.; CORACINI, Maria José. (Org.) O desejo da teoria e a contingência da prática: discursos sobre na sala de aula. Campinas, SP: Mercado de Letras, 2003c.

.; ECKERT-HOFF, Beatriz. (Org.). Escrit(ur)a de si e alteridade no espaço papel-tela. Campinas, SP: Mercado de letras, 2010.

COVRE, Maria de Lourdes M. O que é cidadania. 3 ed. São Paulo: Brasiliense, 2001.

DERRIDA, Jacques. Carta a um amigo japonês. In: OTONI, Paulo.(Org.). Tradução: a prática da diferença. Tradução de Érica Lima. Campinas, SP: Editora da UNICAMP; FAPESP, 1998.

DINIS, Leandro R. A. O Quadro Europeu Comum de Referência para as Línguas": sujeitos, Estados Nacionais e mercado. Anais do SETA, n. 1, 2007.

.; ZOPPI-FONTANA, Monica. G. Declinando a língua pelas injunções do mercado: institucionalização do português língua estrangeira (PLE). Estudos Linguísticos, São Paulo, v. 37 , n.3, p. 89-119, set.-dez. 2008.

FERNANDES, Florestan. O desafio educacional. São Paulo: Cortez Autores Associados, 1989.

FOUCAULT, Michel. O sujeito e o poder. In: DREYFUS, Hubert; RABINOW, Paul. Michel Foucault, uma trajetória filosófica: para além do estruturalismo e da hermenêutica. Tradução de Vera Porto Carrero. Rio de Janeiro: Forense Universitária, 1995. p. 231-249.

. A ordem do discurso: aula inaugural no Collège de France. São Paulo, Edições Loyola, 1996. 

. Resumos do Collège de France (1970-1982). Tradução de Andrea Daher. Rio de Janeiro, Jorge Zahar, 1997.

FREIRE, Paulo. Pedagogia da autonomia: saberes necessários à prática docente. São Paulo: Paz e Terra, 1996.

; HORTON, Myles. O caminho se faz caminhado: conversas sobre educação e mudança social. Petrópolis, Rio de Janeiro: Vozes, 2009.

KANT, Immanuel. Beantwortung der frage: was ist Aufklärung ? In: Berlinische Monatsschrift. Dezember-Heft 1784. S. 481-494. Disponível em: <http://www.unipotsdam.de/u/philosophie/texte/kant/aufklaer.htm>: Acesso em 4 de ago. 2011.

LAWN, Martin. Os professores e a fabricação de identidades. In: jul/dez 2001. Currículo sem Fronteiras, v.1, n.2, p. 117-130,

LESSARD, Claude; TARDIF, Maurice. O trabalho docente: elementos para uma teoria da docência como profissão de interações humanas. Tradução de João Batista Kreuch. 5 ed. Petrópolis, RJ: Vozes, 2005.

LYOTARD, Jean- François. A condição pós-moderna. Tradução Ricardo Correa Barbosa; posfácio Silviano Santiago. 6 ed. Rio de Janeiro: José Olympio, 2000.

MAINGUENEAU, Dominique. Gênese dos discursos. Tradução de Sírio Possenti. Curitiba: Criar, 2007.

MORATO, Edwiges Maria. Da noção de competência no campo da linguística. In: SIGNORINI, Inês. (Org.). Situar a língua(gem). São Paulo: Parábola Editorial, 2008.

MOITA LOPES, Luiz. Paulo. A nova ordem mundial, os parâmetros curriculares nacionais e o ensino de inglês no Brasil: a base intelectual para uma ação política. In: BARBARA, Leila. 
e RAMOS, Rosinda. C. G. (Orgs.). Reflexão e ações no ensinoaprendizagem de línguas. Campinas, SP: Mercado de Letras, 2003. (Coleção As Faces da Linguística Aplicada).

NIETZSCHE, Friedrich. Crepúsculo dos ídolos, ou, como se filosofa com o martelo. Tradução, notas e posfácio de Paulo César de Souza. São Paulo, Companhia das Letras, 2006.

ORLANDI, Eni. Identidade linguística escolar. In: SIGNORINI, Inês. (Org.). Língua(gem) e identidade. Campinas-SP: Mercado de Letras, 1998.

A linguagem e seu funcionamento: as formas do discurso. 4 ed. 3 reimpressão. Campinas, SP: Pontes, 2003.

- Análise de discurso: princípios e procedimentos. Campinas, SP: Pontes, 2007.

. Língua brasileira e outras histórias: discurso sobre a língua e o ensino no Brasil. Campinas, SP: Pontes, 2009.

RAJAGOPALAN, Kanavilil. O conceito de identidade em linguística: é chegada a hora para reconciliação radical? In: SIGNORINI, Inês (Org.). Língua(gem) e identidade. Campinas, SP: Mercado de Letras, 1998.

. Por uma linguística crítica: linguagem, identidade e a questão ética. São Paulo: Parábola Editorial, 2003.

ROBIN, Régine. Le deuil de l'origine: une langue em trop, la langue en moins. Saint-Denis: Presses Universitaires de Vincennes, 1993.

. Le golem de l'ecriture: de l'autofiction au Cybersoi. Montreal: XYZ, 1997.

ROBINS, Kevin. Global times what in the world is going on? In: DU GAY, Paul. (Org.) Production of culture/cultures of production. London: Sage, 1997.

156 Horizontes de Linguística Aplicada, ano 11, n. 2, jul./dez. 2012 
ROJO, Roxane. Modos de transposição dos PCNs às práticas de sala de aula: progressão curricular e projetos. In: . (Org.). A prática de linguagem em sala de aula: praticando os PCNs. Campinas, SP: Mercado de Letras, 2000.

RUSS, Jacqueline. Dicionário de filosofia. Tradução de Alberto Alonso Muñoz, revisão técnica de Scarlett Marton. São Paulo: Scipione, 1994.

SANTOS, Milton. Por uma outra globalização: do pensamento único à consciência universal. 17 ed. Rio de Janeiro: Record, 2008.

SARUP, Madan. Alienação e ensino. In: - Marxismo e educação: abordagem fenomenológica e marxista da educação. Tradução de Waltensir Dutra. Rio de Janeiro: Guanabara, 1986.

SIGNORINI, Inês. Figuras e modelos contemporâneos da subjetividade. In: (Org.). Língua(gem) e identidade. Campinas-SP: Mercado de Letras, 1998.

Metapragmáticas da língua em uso: unidades e níveis de análise In: . (Org.). Situar a língua(gem). São Paulo: Parábola, 2008.

SILVA, Tomaz. T. A produção social da identidade e da diferença. In: (Org.). Identidade e diferença: a perspectiva dos estudos culturais. Vozes: Petrópolis, 2000.

SOARES, Magda. B. Linguagem e escola: uma perspectiva social. 14 ed. São Paulo: Ática, 1996.

- Português na escola: história de uma disciplina curricular In: BAGNO, Marcos. (Org.). Linguística da norma. 2 ed. São Paulo: Edições Loyola, 2001.

SPINOZA, Benedictus. Ética. Tradução e notas de Tomaz Tadeu. Belo Horizonte: Autêntica, 2007. (edição bilíngue Português-Latim). 
A desconstrução da ordem do discurso

VASCONCELLOS. Celso S. Introdução às práticas de mudança. In: - Avaliação da aprendizagem: práticas de mudança. 5 ed. São Paulo: Libertad, 2003.

ZOPPI-FONTANA, Monica. Cidadãos modernos: discurso e representação política. Campinas, SP: Editora da UNICAMP, 1997.

Recebido em: 12/12/2011

Aceito em: 14/11/2012

Title: The deconstruction of the order of discourse and the symbolic violence in the national curriculum guidelines: question on the identity of the subject-teacher.

158 Horizontes de Linguística Aplicada, ano 11, n. 2, jul./dez. 2012 